Keywords: endometrial cancer; endometrial biopsy; endometrial sampling; endometrial carcinoma grading; endometrial histology; endometrial cancer staging

\title{
Assessment of endometrial sampling as a predictor of final surgical pathology in endometrial cancer
}

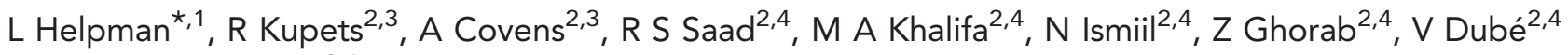 \\ and S Nofech-Mozes ${ }^{2,4}$
}

${ }^{1}$ Department of Gynecologic Oncology, Chaim Sheba Medical Center, Ramat Gan, 5262000, Israel; ${ }^{2}$ Sunnybrook Health Sciences Center, Toronto, Ontario, Canada M4N 3M5; ${ }^{3}$ Department of Gynecologic Oncology, University of Toronto, 27 King's College Circle, Toronto, Ontario, Canada M5S 1A1 and ${ }^{4}$ Department of Laboratory Medicine and Pathobiology, University of Toronto, 27 King's College Circle, Toronto, Ontario, Canada M5S 1A1

Background: The histology and grade of endometrial cancer are important predictors of disease outcome and of the likelihood of nodal involvement. In most centres, however, surgical staging decisions are based on a preoperative biopsy. The objective of this study was to assess the concordance between the preoperative histology and that of the hysterectomy specimen in endometrial cancer.

Methods: Patients treated for endometrial cancer during a 10-year period at a tertiary cancer centre were identified from a prospectively collected pathological database. All pathology reports were reviewed to confirm centralised reporting of the original sampling or biopsy specimens; patients whose biopsies were not reviewed by a dedicated gynaecological pathologist at the treating centre were excluded. Surgical pathology data including histology, grade, depth of myometrial invasion, cervical stromal involvement and lymphovascular space invasion (LVSI) as well as preoperative histology and grade were collected. Preoperative and final tumour cell type and grade were compared and the distribution of other high-risk features was analysed.

Results: A total of 1329 consecutive patients were identified; 653 patients had a centrally reviewed epithelial endometrial cancer on their original biopsy, and are included in this study. Of 255 patients whose biopsies were read as grade 1 (G1) adenocarcinoma, 45 (18\%) were upgraded to grade 2 (G2) on final pathology, 6 (2\%) were upgraded to grade $3(\mathrm{G} 3)$ and 5 (2\%) were read as a nonendometrioid high-grade histology. Overall, of 255 tumours classified as G1 endometrioid cancers on biopsy, 74 (29\%) were either found to be low-grade (G1-2) tumours with deep myometrial invasion, or were reclassified as high-grade cancers (G3 or nonendometrioid histologies) on final surgical pathology. Despite these shifts, we calculate that omitting surgical staging in preoperatively diagnosed G1 endometrioid cancers without deep myometrial invasion would result in missing nodal involvement in only $1 \%$ of cases.

Conclusions: Preoperative endometrial sampling is only a modest predictor of surgical pathology features in endometrial cancer and may underestimate the risk of disease spread and recurrence. In spite of frequent shifts in postoperative vs preoperative histological assessment, the predicted rate of missed nodal metastases with a selective staging policy remains low.

Endometrial cancer is the most common gynaecological malignancy, affecting up to $3 \%$ of women during their lifetime (Siegel et al, 2012). Although generally associated with an excellent prognosis, some endometrial cancers harbour a higher risk for dissemination or recurrence. Optimal surgical management, and specifically - the indications for, and optimal extent of surgical

*Correspondence: Dr L Helpman; E-mail: Limor.helpman@sheba.health.gov.il

Received 3 August 2013; revised 31 October 2013; accepted 4 November 2013; published online 24 December 2013

(c) 2014 Cancer Research UK. All rights reserved 0007-0920/14 
staging have been an ongoing topic of controversy (Mariani et al, 2000; Benedetti Panici et al, 2008; Mariani et al, 2008; Bernardini et al, 2009; Neubauer et al, 2009; Dowdy et al, 2012).

The histological subtype and the grade of endometrial cancer are key features impacting the likelihood of disease spread and recurrence, along with other uterine histopathological factors such as myometrial invasion, cervical stromal involvement and lymphovascular space invasion (LVSI) (Aalders et al, 1980; Creasman et al, 1987; Schink et al, 1987; Morrow et al, 1991; Inoue et al, 1996; Larson et al, 1996; Mariani et al, 2000, 2002; Briet et al, 2005; Nofech-Mozes et al, 2008; Lee et al, 2009; Convery et al, 2011; Milam et al, 2012; Koskas et al, 2013). In fact, classical studies evaluating the association of such pathological features with the risk of nodal spread and disease recurrence (Aalders et al, 1980; Creasman et al, 1987; Morrow et al, 1991) have fuelled the debate on endometrial cancer surgical staging policy. These correlative studies have based their analyses on the features of the final hysterectomy specimen, as opposed to a preoperative endometrial sample. As most histopathological information is not available preoperatively, cell type and grade become key factors available for risk stratification before surgery. Many surgeons advocate for intraoperative assessment of myometrial invasion as an adjunct to preoperative biopsy features. This information is frequently used to determine the extent of the surgical staging procedure.

While it is widely accepted that high-grade endometrial cancers are at high risk for nodal spread and thus require a full surgical staging procedure, low-grade endometrial cancers present a surgical dilemma; in most cases, the risk of nodal involvement is low, and a full lymphadenectomy offers limited or no survival benefit while incurring the risks of an extensive surgical procedure (Benedetti Panici et al, 2008; Bernardini et al, 2009). The question that arises in this situation is whether preoperative endometrial sampling is an adequate predictor of final surgical pathology. Can preoperative information be used to guide surgical staging decisions in endometrial cancers?

\section{SUBJECTS AND METHODS}

This was a retrospective study, designed to assess the concordance between histological subtype and grade on preoperative endometrial sampling and on final surgical pathology, and to evaluate the prevalence and distribution of other histopathological features that impact the risk of nodal spread.

Consecutive patients treated for endometrial cancer between January 1999 and December 2009 at a tertiary cancer centre in Toronto, Canada, were identified from a prospectively maintained pathological database (CoPath Laboratory Information System) following Toronto University Institutional Review Board approval. For cases referred from other institutions with an endometrial biopsy, the policy at our centre has been to review biopsy specimens before surgical decision-making. Similarly, review of surgical pathology specimens is done for endometrial cancers referred for adjuvant treatment following hysterectomy performed at a referring centre. These reviews were conducted by a team of four pathologists with either formal training or specific interest, and $>5$ years subspecialized practice, in gynaecologic pathology. For the purpose of this study, all pathology reports were reviewed to confirm centralised reporting of the original sampling or biopsy specimens; patients whose biopsies had not been re-evaluated by a dedicated gynaecological pathologist at the treating centre were excluded from the study. Patients whose original biopsies did not suggest endometrial cancer or whose histology was not sufficiently informative were also excluded.

Surgical pathological data including histology, grade, depth of myometrial invasion, cervical stromal involvement and LVSI, as well as preoperative histology and grade were collected. Threetiered grading was used for endometrioid adenocarcinomas, based on the FIGO recommendations for nonsquamous architectural grading where grade 1 (G1) has $\leqslant 5 \%$ solid growth pattern, grade 2 (G2) has between 6 and 50\% solid growth pattern, and grade 3 (G3) has $>50 \%$ solid growth pattern. In addition to the nonsquamous solid growth component, a markedly atypical nuclear pattern inappropriate for the architectural grade could increase the final tumour grade by one. Non-endometrioid histological subtypes included papillary serous cancers, carcinosarcomas and clear-cell endometrial cancers and were considered high grade. Deep myometrial invasion was recorded when the tumour invaded the outer half of the myometrium. Lymphovascular space invasion was defined by the presence of malignant cells within endotheliallined spaces on H\&E-stained sections.

Cases were grouped by preoperative and postoperative histology and grade. The correlation between preoperative and final surgical pathological grade was assessed, and the distribution of high-risk uterine features was determined for each subgroup. The depth of myometrial invasion, LVSI and cervical stromal invasion were specifically noted as features incurring a higher risk of lymphatic spread and disease recurrence.

\section{RESULTS}

A total of 1329 consecutive patients treated for endometrial cancer at Toronto Sunnybrook Health Sciences Centre from January 1999 to December 2009 were identified. In all, 394 patients had surgery elsewhere and were reviewed and treated at TSHSC postoperatively based on a review of the surgical pathology specimens, without reviewing the preoperative endometrial biopsy. A total of 19 patients had missing pathology data and were excluded from analysis. Another 34 had biopsies with insufficient tissue, an indefinite diagnosis or a cytology-based diagnosis. Six other patients were misdiagnosed with cervical cancer or sarcomas on initial biopsy, while 20 patients had complex endometrial hyperplasia on initial biopsy. Of the remaining 856 cases, 653 patients had central pathology review of their original biopsy specimens by a dedicated gynaecologic pathologist and were included in this study.

Our series included 464 cases with a preoperative diagnosis of endometrioid adenocarcinoma and 189 who had been diagnosed with non-endometrioid, high-risk histological subtypes: carcinosarcoma, uterine papillary serous carcinoma or clear-cell adenocarcinoma.

Histological data for the entire cohort are presented in Tables $1 \mathrm{~A}$ and $1 \mathrm{~B}$.

The agreement between preoperative and hysterectomy histology and grade varied by tumour subtype and grade. Discordances between preoperative sampling and final surgical pathology are detailed in Tables $1 \mathrm{~A}$ and $1 \mathrm{~B}$ and may be broken down as follows:

Change in FIGO grade (endometrioid tumours). Upgrade: of 255 patients whose biopsies were read as G1 adenocarcinoma, 45 (18\%) were upgraded to grade 2 on final pathology but only $6(2 \%)$ were upgraded to grade 3 (Figure 1). Of 125 G2 biopsies, 20 (16\%) were upgraded to grade 3 on final pathology.

Downgrade: 7 of 84 (8\%) G3 tumours were downgraded on final pathology, with 6 reclassified as G2 and one reclassified as G1. Nineteen (15\%) G2 biopsies were downgraded to G1 on hysterectomy pathology.

Change in cell type (endometrioid to non-endometrioid histologies, and vice versa). A total of 5 of 255 G1 tumours 


\begin{tabular}{|c|c|c|c|c|c|}
\hline & \multicolumn{4}{|c|}{ Hysterectomy histology report } & \multirow[b]{2}{*}{ Total } \\
\hline & G1 endometrioid & G2 endometrioid & G3 endometrioid & HR non-endometrioid & \\
\hline \multicolumn{6}{|c|}{ Biopsy histology report } \\
\hline $\begin{array}{l}\text { G1 endometrioid } \\
\text { G2 endometrioid } \\
\text { G3 endometrioid } \\
\text { HR non-endometrioid }\end{array}$ & $\begin{array}{c}199 \text { (78\%) } \\
19(15 \%) \\
1(1 \%) \\
1(0.5 \%)\end{array}$ & $\begin{array}{l}45(18 \%) \\
74(59 \%) \\
6 \text { (7\%) } \\
3(1.6 \%)\end{array}$ & $\begin{array}{c}6(2 \%) \\
20(16 \%) \\
57(68 \%) \\
9(5 \%)\end{array}$ & $\begin{array}{c}5(2 \%) \\
12(10 \%) \\
20(24 \%) \\
176(93 \%)\end{array}$ & $\begin{array}{r}255 \\
125 \\
84 \\
189 \\
\end{array}$ \\
\hline
\end{tabular}

Table 1B. Detailed histological features of cases grouped by pre- and post-operative histology

\begin{tabular}{|c|c|c|c|c|c|c|c|c|c|c|c|c|c|}
\hline & \multicolumn{13}{|c|}{ Hysterectomy histology report } \\
\hline & \multicolumn{5}{|c|}{ G1 endometrioid } & \multicolumn{5}{|c|}{ G2 endometrioid } & \multirow[b]{2}{*}{ G3 } & \multirow[b]{2}{*}{ HR } & \multirow[b]{2}{*}{ Tota } \\
\hline & Total & DMI & CxSI & LVSI & $\begin{array}{c}\text { LVSI/CXSI } \\
\text { no DMI }\end{array}$ & Total & DMI & $\mathrm{CxSI}$ & LVSI & $\begin{array}{c}\text { LVSI/CxSI } \\
\text { no DMI }\end{array}$ & & & \\
\hline \multicolumn{14}{|l|}{ Biopsy report } \\
\hline G1 endometrioid & $199(78 \%)$ & 44 & 17 & 31 & 15 & $45(18 \%)$ & 19 & 11 & 14 & 6 & $6(2 \%)$ & $5(2 \%)$ & 255 \\
\hline G2 endometrioid & $19(15 \%)$ & 5 & 2 & 2 & 2 & 74 (59\%) & 21 & 19 & 23 & 18 & $20(16 \%)$ & $12(10 \%)$ & 125 \\
\hline G3 endometrioid & $1(1 \%)$ & 0 & 0 & 0 & 0 & $6(7 \%)$ & 4 & 1 & 2 & 0 & 57 (68\%) & $20(24 \%)$ & 84 \\
\hline HR non-endometrioid & $1(0.5 \%)$ & 0 & 1 & 0 & 1 & $3(1.6 \%)$ & 0 & 0 & 0 & 0 & $9(5 \%)$ & $176(93 \%)$ & 189 \\
\hline
\end{tabular}
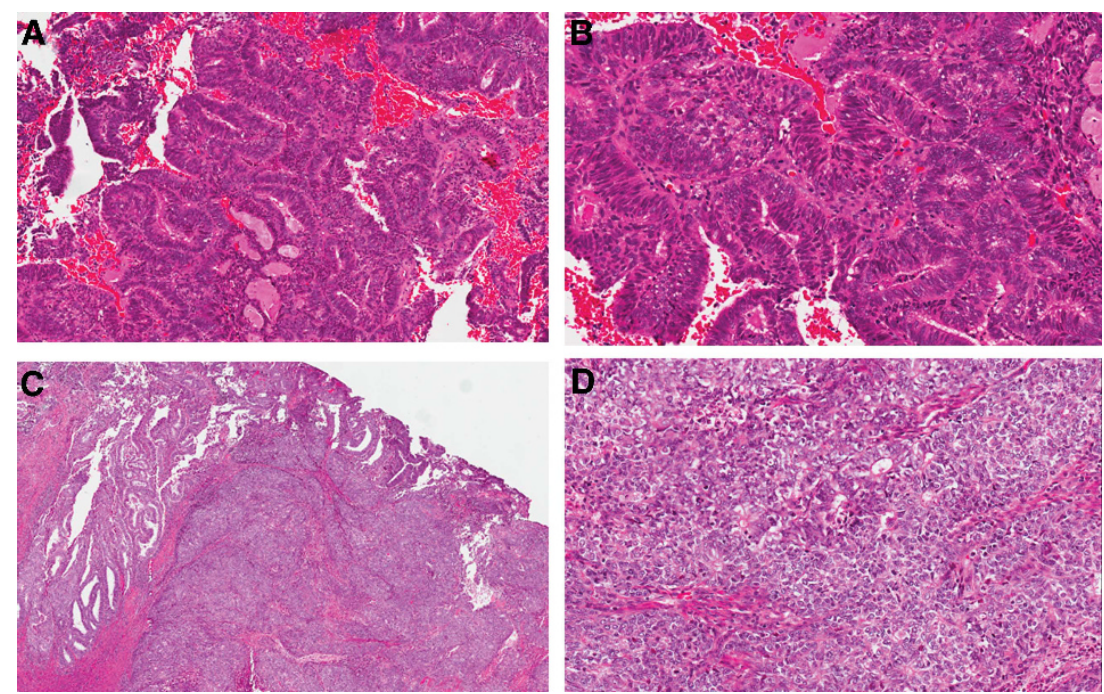

Figure 1. Endometrial biopsy: endometrioid adenocarcinoma FIGO grade 1, low (A) and high (B) power. Hysterectomy: subsequent resection reveals significant solid component that was not represented in the biopsy. The final grade was FIGO grade 3 . Low (C) and high (D) power.

(2\%) and 12 of 125 G2 tumours (10\%) were reclassified as a high risk, non-endometrioid histological subtype on final pathology, including 11 serous tumours, 5 carcinosarcomas and 1 clear cell endometrial cancer (Figure 2). This also occurred in 20 of 84 (24\%) G3 cancers (6 serous cancers, 7 carcinosarcomas and 7 clear cell carcinomas).

Only four (2\%) preoperatively defined high-risk histology specimens, including four serous cancers and one mixed clear cell carcinoma were reclassified on final surgical pathology as lowgrade (G1-2) endometrioid cancers.
Change in risk stratification based on other histopathological parameters. Of 255 preoperatively diagnosed G1 endometrioid cancers, 63 (25\%) retained a low-grade (G1-2) diagnosis on final surgical histology but were found to have deep myometrial invasion; an additional 21 (8\%) had LVSI or cervical stromal invasion without deep myometrial invasion. Of 125 preoperatively diagnosied G2 endometrioid tumours, 26 (21\%) were classified postoperatively as G1-2 tumours with deep myometrial invasion, and an additional 20 (16\%) were classified as G1-2 

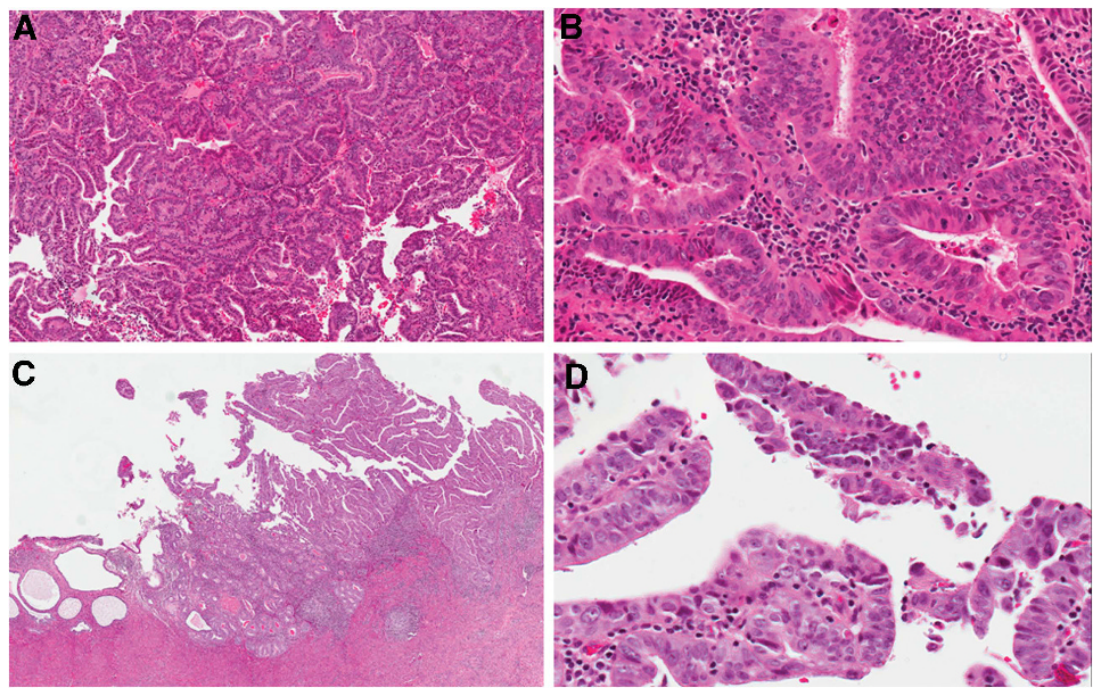

Figure 2. Endometrial biopsy: endometrioid adenocarcinoma FIGO grade 1, low (A) and high (B) power. Hysterectomy: subsequent resection reveals a serous carcinoma component that was not sampled in the biopsy. Overall, serous carcinoma accounted for $70 \%$ of the tumour and endometrioid for 30\%. Low (C) and high (D) power.

tumours but had LVSI or cervical stromal involvement (Table 1B).

Overall, of 255 tumours classified as G1 endometrioid cancers on biopsy, 74 (29\%) were either found to be low grade (G1-2) tumours with deep myometrial invasion, or were reclassified as high-grade cancers (G3 or non-endometrioid histologies) on final surgical pathology; 21 others that retained a low grade classification on surgical pathology $(8 \%)$ had LVSI or cervical stromal invasion in the absence of deep myometrial invasion (Figure 3).

A predictive model of lymphatic risk based on pre/intraoperative assessment. Using data from GOG-33 on surgical pathology correlates and combining it with our data on biopsy-to-surgical pathology shifts, a predictive model can be developed to guide surgical staging decisions (Table 2). For example, the predicted prevalence of lymph node involvement in a cohort of 100 patients with G1 endometrioid tumours on biopsy would in fact comprise the expected rate of lymphatic dissemination in 78 G1 endometrioid tumours of which 17 have deep myometrial invasion, 18 G2 endometioid tumours of which 8 have deep myometrial invasion, 2 G3 endometrioid tumours and 2 high-risk nonendometrioid tumours. Omitting staging in this cohort of G1 endometrioid cancers would result in missing 3\% nodal metastases in the cases that remain G1 on final pathology, $9 \%$ nodal metastases in those reclassified as G2, 18\% nodal metastases in those reclassified as G3 and 20\% nodal metastases in the cases reclassified as non-endometrioid high risk histologies for a total of 5 cases in 100 or $5 \%$. Based on the grade distribution found in this analysis for endometrioid adenocarcinomas (55\% G1 tumours, $27 \%$ G2 tumours and 18\% G3 tumours) these would represent 3\% of the total cohort. Omitting staging only in preoperatively defined G1 endometrioid cancers with intraoperatively determined deep myometrial invasion, assuming 90\% accuracy, would result in missing less involved nodes; specifically, $90 \%$ of 17 G1 tumours and $90 \%$ of 8 G2 tumours with deep myometrial invasion would be identified and staged, of which $11 \%$ and $19 \%$, respectively, would be expected to have lymphatic dissemination, for a total of 3 identified cases in $100 \mathrm{G} 1$ endometrioid tumours or 2 missed cases, representing $1 \%$ of the total cohort.

The predicted outcomes of various staging policies based on preoperative and intraoperative information are summarised in Table 2.

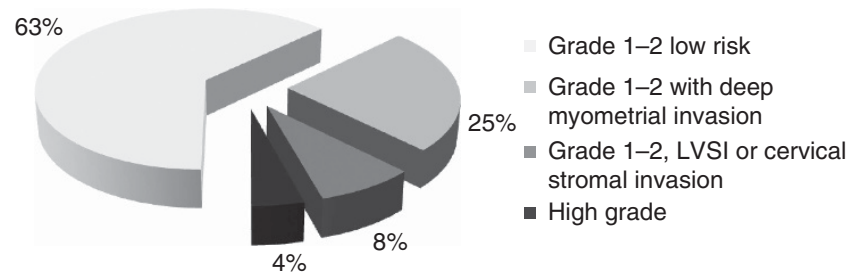

Figure 3. Final surgical pathology histological features of preoperatively defined grade 1 endometrioid adenocarcinoma cases grade 1-2 low risk - with no high-risk features such as deep myometrial invasion, LVSI or cervical stromal invasion LVSI.

\begin{tabular}{|c|c|c|c|c|c|}
\hline \multicolumn{4}{|c|}{ Staging information } & \multirow[b]{2}{*}{ NPV } & \multirow[b]{2}{*}{ FN } \\
\hline Patients staged & $n$ & $\begin{array}{l}\text { Node-positive } \\
\text { cases identified }\end{array}$ & $\begin{array}{l}\text { Node-positive } \\
\text { cases missed }\end{array}$ & & \\
\hline Everyone & 1000 & 100 & 0 & $100 \%$ & $0 \%$ \\
\hline No one & 0 & 0 & 100 & $90 \%$ & $10 \%$ \\
\hline G3 only & 180 & 34 & 66 & $93 \%$ & $7 \%$ \\
\hline G2-3 & 450 & 72 & 28 & $97 \%$ & $3 \%$ \\
\hline G2-3 and G1DMl & 585 & 89 & 11 & $99 \%$ & $1 \%$ \\
\hline \multicolumn{6}{|c|}{$\begin{array}{l}\text { Abbreviations: DMI = deep myometrial invasion; } \mathrm{FN}=\text { false negative; } \mathrm{G} 1,2,3=\mathrm{Grade} 1,2 \\
\text { and } 3 \text { endometrioid adenocarcinoma of the endometrium; } \mathrm{NPV}=\text { negative predictive value. } \\
\text { Assumptions: } 10 \% \text { overall lymph node involvement: } 3 \% \text { for } \mathrm{G} 1,9 \% \text { for } \mathrm{G} 2,19 \% \text { for } \mathrm{G} 3 \\
\text { (GOG33 data). Grade distribution of } 55 \% \mathrm{G} 1,27 \% \mathrm{G} 2,18 \% \mathrm{G} 3 \text { tumours. A total of } 25 \% \text { of } \\
\text { preoperatively defined } \mathrm{G} 1 \text { tumours have deep myometrial invasion. }\end{array}$} \\
\hline
\end{tabular}

\section{DISCUSSION}

Pathological information is often used to stratify endometrial cancers into risk groups, based on low and high risk for lymphatic dissemination and disease recurrence. Early studies evaluating the 
correlation between local tumour features and the risk of node involvement and disease recurrence have based their analyses on pathological characteristics of the final hysterectomy specimen (Aalders et al, 1980; Creasman et al, 1987; Morrow et al, 1991).

GOG33 (Creasman et al, 1987) determined independent prognostic factors for lymphatic dissemination in $>600$ primarily endometrioid endometrial cancer cases apparently limited to the uterus. Tumour grade, depth of myometrial invasion and LVSI as well as tumour location (cervix/isthmus $v s$ corpus) and extrauterine spread all significantly increased the risk of lymph node involvement. A landmark trial on postoperative radiation treatment by Aalders et al (1980) underlined the importance of the same set of features: grade, depth of myometrial invasion and LVSI, as prognostic factors for disease recurrence.

Efforts to define guidelines directing surgical staging and its extent in endometrial cancers have relied heavily on the data generated by these two landmark studies. Although highly informative, most of the features found to significantly impact the risk of lymphatic dissemination cannot be determined preoperatively: LVSI, myometrial and cervical invasion, peritoneal cytology and other sites of peritoneal spread.

Some prognostic features, such as tumour size and location (Schink et al, 1987; Mariani et al, 2000; Convery et al, 2011; Boren et al, 2012; Milam et al, 2012; Alhilli et al, 2013; Laufer et al, 2013), may be assessed with preoperative imaging or intraoperatively by frozen section, although this may harbour some pitfalls, as for example with multifocal lesions. Assessment of the depth of myometrial invasion by preoperative imaging is not sufficiently reliable (Savelli et al, 2012; Antonsen et al, 2013; Kisu et al, 2013; $\mathrm{Wu}$ et al, 2013); however, intraoperative assessment with either visual inspection (Doering et al, 1989; Traen et al, 2007; Marcickiewicz and Sundfeldt, 2011) or frozen section evaluation (Fanning et al, 1990; Shim et al, 1992; Mariani et al, 2000; Alhilli et al, 2012; Kumar et al, 2012; Kisu et al, 2013) was found to be similarly accurate, correlating with final pathological evaluation $90-95 \%$ of the time.

However, intraoperative consultation for every case with preoperative diagnosis of low-grade endometrioid adenocarcinoma is costly and not available in some centres, where the pathology service may be off-site. Furthermore, intraoperative information is advantageous only when lymphadenectomy can be performed, that is, when surgery is performed by a gynaecologic oncologist, limiting the possibility of triaging low-grade cases to community hospitals preoperatively.

The only predictive histologic features determined preoperatively are cell type and tumour grade. High grade (G3) endometrioid cancers as well as non-endometrioid histological subtypes are at high risk for early spread and recurrence. The risk of microscopic lymph node involvement was found to be as high as $20 \%$ for G3 endometrioid tumours (Creasman et al, 1987; Lee et al, 2009; Milam et al, 2012), 20\% for clear-cell endometrial cancers (Thomas et al, 2008), 20-50\% for uterine serous cancers in different reports (Goff et al, 1994; Hamilton et al, 2006) and 15-20\% for carcinosarcomas (Silverberg et al, 1990; Temkin et al, 2007; Nemani et al, 2008).

On the other hand, low-grade endometrioid endometrial cancers are consistently found to have a low risk for lymphatic dissemination and recurrence ranging from $0-10 \%$, depending on the presence of other features (Creasman et al, 1987; Morrow et al, 1991; Mariani et al, 2002). This has led to significant variability in surgical practice, with many centres advocating a selective staging policy. At the time of this audit, the policy at our center was to forgo staging in G1 endometrioid carcinomas.

The accuracy and reliability of preoperative histologic assessement were the focus of this study. Our data demonstrates that nonendometrioid, high-risk histologies have the highest concordance for preoperative and postoperative pathology interpretation: 176 of 189 (93\%) retained their preoperative classification. These findings are in line with another report from our group demonstrating robust inter-observer agreement in the diagnosis of non-endometrioid histology (Nofech-Mozes et al, 2012).

Endometrioid tumours showed more frequent shifts between risk groups when comparing pre-operative and post-operative histology. Twenty two per cent of tumours defined as G1 on biopsy were upgraded on final pathology, as were $26 \%$ of G2 tumours. On the other hand, $8 \%$ of preoperatively defined G3 tumours and $15 \%$ of preoperatively defined G2 tumours were downgraded on final pathological evaluation.

Our data generally corroborates findings in previous studies, quoting rates of $16-40 \%$ updgrading from preoperatively diagnosed G1-2 endometrioid adenocarcinomas (Petersen et al, 2000; Frumovitz et al, 2004; Leitao et al, 2008; Neubauer et al, 2009; Leitao et al, 2010). These grade shifts on final pathological assessments may be partly explained by the volume of tissue available for examination, and in fact have been shown to be less frequent when preoperative sampling is done by $\mathrm{D} \& \mathrm{C}$ as compared with office aspiration biopsy (Leitao et al, 2009). A larger volume of tissue may allow better assessment of the solid growth component, and avoid misleading sampling issues in mixed endometrioid/ non-endometrioid tumours. Interobserver variability is another significant factor impacting on classification shifts, and is especially notable for nuclear grading (Scholten et al, 2004; Nofech-Mozes et al, 2012). It should be noted, however, that in accord with the data presented here, the vast majority of shifts occur from low(G1) to intermediate (G2) grade; only a small minority $(0.5-5 \%$ in the different studies) of G1 tumours are reclassified as high grade on final surgical pathology.

We also questioned how well preoperative pathological information correlates with overall histological risk stratification. Tumour grade and histology alone are insufficient predictors of tumour behaviour; in fact, depth of invasion, cervical stromal invasion and LVSI have been consistently found to correlate with the risk of lymphatic dissemination and factor into most risk prediction models (Creasman et al, 1987; Creutzberg et al, 2000; Mariani et al, 2008; Nout et al, 2011; Boren et al, 2012; Milam et al, 2012). In this analysis, 95 of 255 (37\%) preoperative defined G1 cases (Figure 3) and 78 of $125(62 \%)$ preoperatively defined G2 tumours would be classified as intermediate to high risk on final surgical pathology on the basis of grade/histology, depth of invasion, LVSI or cervical stromal invasion, with a $\geqslant 10 \%$ risk of lymphatic dissemination at the time of surgery (Table $1 \mathrm{~B}$, Figure 3). A recent Italian study argued that preoperative tumour risk assessment was a strong predictor of risk (Maneschi et al, 2012). Our observations suggest that preoperative biopsy may in fact significantly underestimate tumour risk.

The issue of shifts between pre-operative and final surgical pathology interpretation only becomes meaningful if preoperative histological features are used to guide surgical staging decisions. In spite of the frequent shift from a low-risk to a high-risk classification on final pathology, avoiding lymphadenectomy in low-grade endometrial cancer has been shown to have no deleterious impact on overall or disease-free survival (Benedetti Panici et al, 2008; Bernardini et al, 2009; Neubauer et al, 2009). Using data from Creasman's GOG-33 trial combined with our data on pre- $v s$ post-operative histology and grade shifts, a predictive model can be developed to guide surgical staging decisions. The predicted outcomes of various staging policies based on preoperative and intraoperative information are summarised in Table 2. Based on these calculations, the negative predictive value of a selective lymphadenectomy policy for G2-3 endometrioid cancers only would be $97 \%$, with a $3 \%$ rate of missed nodal involvement (false negatives). This low false negative rate explains the similar survival and recurrence outcomes when employing 
such a staging policy, as compared with a universal staging policy. Moreover, selective lymphadenectomy using grade and intraoperative assessment of myometrial invasion as suggested by the Mayo Clinic group (Mariani et al, 2008) would yield a negative predictive value of $99 \%$ with only $1 \%$ node-positive cases missed, while avoiding lymphadenectomy in $>40 \%$ of patients.

This model demonstrates that in spite of predicted shifts in pathology and grading and the addition of other uterine risk factors, basing staging decisions on preoperative and intraoperative information will result in a small number of missed nodal metastases.

Perceived advantages of surgical staging include collecting prognostic information, guiding adjuvant treatment decisions and a potential therapeutic advantage with the removal of pathologically involved lymph nodes. Although no study has been able to demonstrate a therapeutic benefit to lymphadenectomy (Mariani et al, 2000; Benedetti Panici et al, 2008; Kitchener et al, 2009), determining lymph node status is key to adjuvant treatment decisions: on one hand, it limits the use of unnecessary radiation for high-risk patients demonstrated to have localised disease; on the other, surgical staging identifies patients who may benefit from systemic treatment, which has been shown to improve overall survival in advanced disease (Randall et al, 2006). Selective lymphadenectomy based on risk factors available pre- and intraoperatively may maximise the benefits of surgical staging while limiting the complications of a more extensive surgical procedure. The selection of an acceptable cutoff for selective staging may vary according to a surgeon's or institution's philosophy, but can be guided by the predictive model suggested here. This model is innovative in accounting for the expected shifts between pre- and post-operative pathological diagnoses.

\section{CONCLUSIONS}

Preoperative endometrial sampling is only a modest predictor of final histology in endometrial cancer, and underestimates the potential risk of nodal spread and disease recurrence. Nevertheless, selecting cases for surgical staging based on pre- and intraoperative information would result in an acceptably low predicted rate of missed nodal metastases. In fact, omitting lymphadenectomy in low-risk endometrioid tumours, defined as G1 tumours without deep myometrial invasion as assessed intraoperatively, would only fail to identify $1 \%$ of node-positive cases. Decisions regarding a universal $v s$ a selective surgical staging policy, and setting an acceptable cutoff for selective staging will undoubtedly vary between institutions and surgeons.

\section{REFERENCES}

Aalders J, Abeler V, Kolstad P, Onsrud M (1980) Postoperative external irradiation and prognostic parameters in stage I endometrial carcinoma: clinical and histopathologic study of 540 patients. Obstet Gynecol 56: 419-427.

Alhilli MM, Podratz KC, Dowdy SC, Bakkum-Gamez JN, Weaver AL, Mcgree ME, Kumar S, Keeney GL, Cliby WA, Mariani A (2012) Preoperative biopsy and intraoperative tumor diameter predict lymph node dissemination in endometrial cancer. Gynecol Oncol 128: 294-299.

Alhilli MM, Podratz KC, Dowdy SC, Bakkum-Gamez JN, Weaver AL, Mcgree ME, Kumar S, Keeney GL, Cliby WA, Mariani A (2013) Preoperative biopsy and intraoperative tumor diameter predict lymph node dissemination in endometrial cancer. Gynecol Oncol 128: 294-299.

Antonsen SL, Jensen LN, Loft A, Berthelsen AK, Costa J, Tabor A, Qvist I, Hansen MR, Fisker R, Andersen ES, Sperling L, Nielsen AL, Asmussen J, Hogdall E, Fago-Olsen CL, Christensen IJ, Nedergaard L, Jochumsen K, Hogdall C (2013) MRI, PET/CT and ultrasound in the preoperative staging of endometrial cancer - a multicenter prospective comparative study. Gynecol Oncol 128: 300-308.

Benedetti Panici P, Basile S, Maneschi F, Alberto Lissoni A, Signorelli M, Scambia G, Angioli R, Tateo S, Mangili G, Katsaros D, Garozzo G, Campagnutta E, Donadello N, Greggi S, Melpignano M, Raspagliesi F, Ragni N, Cormio G, Grassi R, Franchi M, Giannarelli D, Fossati R, Torri V, Amoroso M, Croce C, Mangioni C (2008) Systematic pelvic lymphadenectomy $v s$ no lymphadenectomy in early-stage endometrial carcinoma: randomized clinical trial. J Natl Cancer Inst 100: 1707-1716.

Bernardini MQ, May T, Khalifa MA, Bland AE, Nofech-Mozes S, Berchuck A, Covens A, Havrilesky L (2009) Evaluation of two management strategies for preoperative grade 1 endometrial cancer. Obstet Gynecol 114: 7-15.

Boren T, Lea J, Kehoe S, Miller DS, Richardson D (2012) Lymph node metastasis in endometrioid adenocarcinomas of the uterine corpus with occult cervical involvement. Gynecol Oncol 127: 43-46.

Briet JM, Hollema H, Reesink N, Aalders JG, Mourits MJ, Ten Hoor KA, Pras E, Boezen HM, Van Der Zee AG, Nijman HW (2005) Lymphvascular space involvement: an independent prognostic factor in endometrial cancer. Gynecol Oncol 96: 799-804.

Convery PA, Cantrell LA, Di Santo N, Broadwater G, Modesitt SC, Secord AA, Havrilesky LJ (2011) Retrospective review of an intraoperative algorithm to predict lymph node metastasis in low-grade endometrial adenocarcinoma. Gynecol Oncol 123: 65-70.

Creasman WT, Morrow CP, Bundy BN, Homesley HD, Graham JE, Heller PB (1987) Surgical pathologic spread patterns of endometrial cancer. A Gynecologic Oncology Group Study. Cancer 60: 2035-2041.

Creutzberg CL, Van Putten WL, Koper PC, Lybeert ML, Jobsen JJ, Warlam-Rodenhuis CC, De Winter KA, Lutgens LC, Van Den Bergh AC, Van De Steen-Banasik E, Beerman H, Van Lent M (2000) Surgery and postoperative radiotherapy versus surgery alone for patients with stage-1 endometrial carcinoma: multicentre randomised trial. PORTEC Study Group. Post Operative Radiation Therapy in Endometrial Carcinoma. Lancet 355: 1404-1411.

Doering DL, Barnhill DR, Weiser EB, Burke TW, Woodward JE, Park RC (1989) Intraoperative evaluation of depth of myometrial invasion in stage I endometrial adenocarcinoma. Obstet Gynecol 74: 930-933.

Dowdy SC, Borah BJ, Bakkum-Gamez JN, Weaver AL, Mcgree ME, Haas LR, Keeney GL, Mariani A, Podratz KC (2012) Prospective assessment of survival, morbidity, and cost associated with lymphadenectomy in low-risk endometrial cancer. Gynecol Oncol 127: 5-10.

Fanning J, Tsukada Y, Piver MS (1990) Intraoperative frozen section diagnosis of depth of myometrial invasion in endometrial adenocarcinoma. Gynecol Oncol 37: 47-50.

Frumovitz M, Singh DK, Meyer L, Smith DH, Wertheim I, Resnik E, Bodurka DC (2004) Predictors of final histology in patients with endometrial cancer. Gynecol Oncol 95: 463-468.

Goff BA, Kato D, Schmidt RA, Ek M, Ferry JA, Muntz HG, Cain JM, Tamimi HK, Figge DC, Greer BE (1994) Uterine papillary serous carcinoma: patterns of metastatic spread. Gynecol Oncol 54: 264-268.

Hamilton CA, Cheung MK, Osann K, Chen L, Teng NN, Longacre TA, Powell MA, Hendrickson MR, Kapp DS, Chan JK (2006) Uterine papillary serous and clear cell carcinomas predict for poorer survival compared to grade 3 endometrioid corpus cancers. Br J Cancer 94: 642-646.

Inoue Y, Obata K, Abe K, Ohmura G, Doh K, Yoshioka T, Hoshiai H, Noda K (1996) The prognostic significance of vascular invasion by endometrial carcinoma. Cancer 78: 1447-1451.

Kisu I, Banno K, Lin LY, Ueno A, Abe T, Kouyama K, Okuda S, Masugi Y, Umene K, Nogami Y, Tsuji K, Masuda K, Ueki A, Kobayashi Y, Yamagami W, Susumu N, Aoki D (2013) Preoperative and intraoperative assessment of myometrial invasion in endometrial cancer: comparison of magnetic resonance imaging and frozen sections. Acta Obstet Gynecol Scand 92: 525-535.

Kitchener H, Swart AM, Qian Q, Amos C, Parmar MK (2009) Efficacy of systematic pelvic lymphadenectomy in endometrial cancer (MRC ASTEC trial): a randomised study. Lancet 373: 125-136.

Koskas M, Bassot K, Graesslin O, Aristizabal P, Barranger E, Clavel-Chapelon F, Haddad B, Luton D, Darai E, Rouzier R (2013) Impact of lymphovascular space invasion on a nomogram for predicting lymph node metastasis in endometrial cancer. Gynecol Oncol 129: 292-297.

Kumar S, Medeiros F, Dowdy SC, Keeney GL, Bakkum-Gamez JN, Podratz KC, Cliby WA, Mariani A (2012) A prospective assessment of the reliability of frozen section to direct intraoperative decision making in endometrial cancer. Gynecol Oncol 127: 525-531. 
Larson DM, Connor GP, Broste SK, Krawisz BR, Johnson KK (1996) Prognostic significance of gross myometrial invasion with endometrial cancer. Obstet Gynecol 88: 394-398.

Laufer J, Scasso S, Papadia A, Sosa C, Cirillo F, Raspagliesi F (2013) Association between tumor diameter and lymphovascular space invasion among women with early-stage endometrial cancer. Int J Gynaecol Obstet 123: $142-145$

Lee KB, Ki KD, Lee JM, Lee JK, Kim JW, Cho CH, Kim SM, Park SY, Jeong DH, Kim KT (2009) The risk of lymph node metastasis based on myometrial invasion and tumor grade in endometrioid uterine cancers: a multicenter, retrospective Korean study. Ann Surg Oncol 16: 2882-2887.

Leitao Jr MM, Kehoe S, Barakat RR, Alektiar K, Gattoc LP, Rabbitt C, Chi DS, Soslow RA, Abu-Rustum NR (2008) Accuracy of preoperative endometrial sampling diagnosis of FIGO grade 1 endometrial adenocarcinoma. Gynecol Oncol 111: 244-248.

Leitao Jr MM, Kehoe S, Barakat RR, Alektiar K, Gattoc LP, Rabbitt C, Chi DS, Soslow RA, Abu-Rustum NR (2009) Comparison of D\&C and office endometrial biopsy accuracy in patients with FIGO grade 1 endometrial adenocarcinoma. Gynecol Oncol 113: 105-108.

Leitao Jr MM, Kehoe S, Barakat RR, Alektiar K, Rabbitt C, Chi DS, Soslow RA, Abu-Rustum NR (2010) Endometrial sampling diagnosis of FIGO grade 1 endometrial adenocarcinoma with a background of complex atypical hyperplasia and final hysterectomy pathology. Am J Obstet Gynecol 202: 278, e1-e6.

Maneschi F, Ceccacci I, Perugini A, Pane C, Simeone A, Manicone A (2012) Endometrial cancer: prognostic significance of risk classification based on pre-intraoperative findings. Arch Gynecol Obstet 285: 521-527.

Marcickiewicz J, Sundfeldt K (2011) Accuracy of intraoperative gross visual assessment of myometrial invasion in endometrial cancer. Acta Obstet Gynecol Scand 90: 846-851.

Mariani A, Dowdy SC, Cliby WA, Gostout BS, Jones MB, Wilson TO, Podratz KC (2008) Prospective assessment of lymphatic dissemination in endometrial cancer: a paradigm shift in surgical staging. Gynecol Oncol 109: 11-18.

Mariani A, Webb MJ, Keeney GL, Aletti G, Podratz KC (2002) Predictors of lymphatic failure in endometrial cancer. Gynecol Oncol 84: 437-442.

Mariani A, Webb MJ, Keeney GL, Haddock MG, Calori G, Podratz KC (2000) Low-risk corpus cancer: is lymphadenectomy or radiotherapy necessary? Am J Obstet Gynecol 182: 1506-1519.

Milam MR, Java J, Walker JL, Metzinger DS, Parker LP, Coleman RL. Gynecologic Oncology, G. (2012) Nodal metastasis risk in endometrioid endometrial cancer. Obstet Gynecol 119: 286-292.

Morrow CP, Bundy BN, Kurman RJ, Creasman WT, Heller P, Homesley HD, Graham JE (1991) Relationship between surgical-pathological risk factors and outcome in clinical stage I and II carcinoma of the endometrium: a Gynecologic Oncology Group study. Gynecol Oncol 40: 55-65.

Nemani D, Mitra N, Guo M, Lin L (2008) Assessing the effects of lymphadenectomy and radiation therapy in patients with uterine carcinosarcoma: a SEER analysis. Gynecol Oncol 111: 82-88.

Neubauer NL, Havrilesky LJ, Calingaert B, Bulusu A, Bernardini MQ, Fleming ND, Bland AE, Secord AA (2009) The role of lymphadenectomy in the management of preoperative grade 1 endometrial carcinoma. Gynecol Oncol 112: 511-516.

Nofech-Mozes S, Ackerman I, Ghorab Z, Ismiil N, Thomas G, Covens A, Khalifa MA (2008) Lymphovascular invasion is a significant predictor for distant recurrence in patients with early-stage endometrial endometrioid adenocarcinoma. Am J Clin Pathol 129: 912-917.
Nofech-Mozes S, Ismiil N, Dube V, Saad RS, Ghorab Z, Grin A, Ackerman I, Khalifa MA (2012) Interobserver agreement for endometrial cancer characteristics evaluated on biopsy material. Obstet Gynecol Int 2012: 414086.

Nout RA, Van De Poll-Franse LV, Lybeert ML, Warlam-Rodenhuis CC, Jobsen JJ, Mens JW, Lutgens LC, Pras B, Van Putten WL, Creutzberg CL (2011) Long-term outcome and quality of life of patients with endometrial carcinoma treated with or without pelvic radiotherapy in the post operative radiation therapy in endometrial carcinoma 1 (PORTEC-1) trial. J Clin Oncol 29: 1692-1700.

Petersen RW, Quinlivan JA, Casper GR, Nicklin JL (2000) Endometrial adenocarcinoma - presenting pathology is a poor guide to surgical management. Aust N Z J Obstet Gynaecol 40: 191-194.

Randall ME, Filiaci VL, Muss H, Spirtos NM, Mannel RS, Fowler J, Thigpen JT, Benda JA (2006) Randomized phase III trial of wholeabdominal irradiation versus doxorubicin and cisplatin chemotherapy in advanced endometrial carcinoma: a Gynecologic Oncology Group Study. J Clin Oncol 24: 36-44.

Savelli L, Testa AC, Mabrouk M, Zannoni L, Ludovisi M, Seracchioli R, Scambia G, De Iaco P (2012) A prospective blinded comparison of the accuracy of transvaginal sonography and frozen section in the assessment of myometrial invasion in endometrial cancer. Gynecol Oncol 124: 549-552.

Schink JC, Lurain JR, Wallemark CB, Chmiel JS (1987) Tumor size in endometrial cancer: a prognostic factor for lymph node metastasis. Obstet Gynecol 70: 216-219.

Scholten AN, Smit VT, Beerman H, Van Putten WL, Creutzberg CL (2004) Prognostic significance and interobserver variability of histologic grading systems for endometrial carcinoma. Cancer 100: 764-772.

Shim JU, Rose PG, Reale FR, Soto H, Tak WK, Hunter RE (1992) Accuracy of frozen-section diagnosis at surgery in clinical stage I and II endometrial carcinoma. Am J Obstet Gynecol 166: 1335-1338.

Siegel R, Naishadham D, Jemal A (2012) Cancer statistics, 2012. CA Cancer J Clin 62: 10-29.

Silverberg SG, Major FJ, Blessing JA, Fetter B, Askin FB, Liao SY, Miller A (1990) Carcinosarcoma (malignant mixed mesodermal tumor) of the uterus. A Gynecologic Oncology Group pathologic study of 203 cases. Int J Gynecol Pathol 9: 1-19.

Temkin SM, Hellmann M, Lee YC, Abulafia O (2007) Early-stage carcinosarcoma of the uterus: the significance of lymph node count. Int J Gynecol Cancer 17: 215-219.

Thomas M, Mariani A, Wright JD, Madarek EO, Powell MA, Mutch DG, Podratz KC, Dowdy SC (2008) Surgical management and adjuvant therapy for patients with uterine clear cell carcinoma: a multi-institutional review. Gynecol Oncol 108: 293-297.

Traen K, Holund B, Mogensen O (2007) Accuracy of preoperative tumor grade and intraoperative gross examination of myometrial invasion in patients with endometrial cancer. Acta Obstet Gynecol Scand 86: 739-741.

Wu LM, Xu JR, Gu HY, Hua J, Haacke EM, Hu J (2013) Predictive value of T2-weighted imaging and contrast-enhanced MR imaging in assessing myometrial invasion in endometrial cancer: a pooled analysis of prospective studies. Eur Radiol 23: 435-449.

This work is published under the standard license to publish agreement. After 12 months the work will become freely available and the license terms will switch to a Creative Commons AttributionNonCommercial-Share Alike 3.0 Unported License. 